\title{
Modeling Determinants Of Debt Default In International Finance: Isolation, Magnitude, And Prediction
}

Robert G. Vambery, (E-mail: rvambery@pace.edu), Pace University James W. Gabberty, (E-mail: jgabberty@ pace.edu), Pace University

\begin{abstract}
The current Argentine debt crises scenario is representative of a climate of financial irresponsibility that does not show signs of waning and has regretfully become a permanent feature of the international financial landscape.

This ongoing study examines the evolution of irresponsible borrowing and lending behavior. Through the development of interpretive graphical models, the study hopes to demonstrate the predictability of defaults and to help in the detection of their timing and magnitudes. The isolation of these two factors may assist the global financial community to develop strategies to forestall and/or soften the impacts associated with financial catastrophes of this type.
\end{abstract}

\section{Introduction}

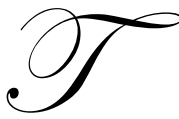

he age-old adage that there are two certainties in life, that is, death and taxes, is in dire need of revision for the twenty-first century world of international finance. During much of the twentieth century, the world financial community tried to create regulations, rules of conduct, codes of ethics, and institutional structures that would help assure stability and reliability for large-scale international financial transactions and for financial relations among nations. The outcome of these efforts is lackluster in light of recurring global financial crises.

The in progress default by the government of Argentina, for example, both on domestic debt and on largescale foreign debts is the most recent manifestation of predictable crises arising from incurring unsustainable financial obligations and from excessive hard currency borrowing. The availability of funds from various sources does not lead to substantial punitive consequences in the short-term. However, longer-term consequences of great severity eventually do result as the sources of income needed to service the rising debt fail to keep pace with the borrowing activity. The occurrence of default situations is then predictable because their occurrence is inevitable. Nonetheless, their timing and magnitudes still remain uncertain and are important subjects for forecasting purposes. The certainty of debt defaults thus becomes the third guaranteed event - along with death and taxes.

\section{Borrowing Modalities after Default}

There are several ways that borrowers may obtain needed monies. Ideally, borrowers ought to anticipate their future needs for money and enter into debt obligations having well defined and predictable repayment schedules. In this way, both lenders and borrowers can forecast future financing activities and achieve a measure of normalcy and stability. However, failure by borrowers to anticipate fluctuations in their abilities to adhere to repayment schedules and to establish reserves to accommodate these variations can result in erratic borrowing behavior. When this happens, predictability is lost and a default condition may occur.

Readers with comments or questions are encouraged to contact the authors via email. 
After a default event, borrowers may obtain new loans, taking either an aggressive or a conservative approach, as identified in the patterns of Figure 1. Curve A in this illustration depicts a borrower who secures loans through a stepped up pace, often the result of attempts to stave off civil unrest or other catastrophes. When this occurs, borrowing after the default resumes at a rapid or exaggerated rate. However, the borrower's (or the borrowing country's) problems may be so huge that a gigantic loan needs to be obtained, that is, borrowing escalates initially at a steep rate after which its increases dampen to a slower rate.

Alternately, the borrowers may start with a cautionary approach in seeking monies, and then become more assertive with the size or frequency of loan agreements as the borrowers' abilities to demonstrate improved earnings conditions and enhanced reliability become evident. Curve B in Figure 1 illustrates this cautionary rate of borrowing.

Figure 1 - Resumption of Borrowing Alternatives

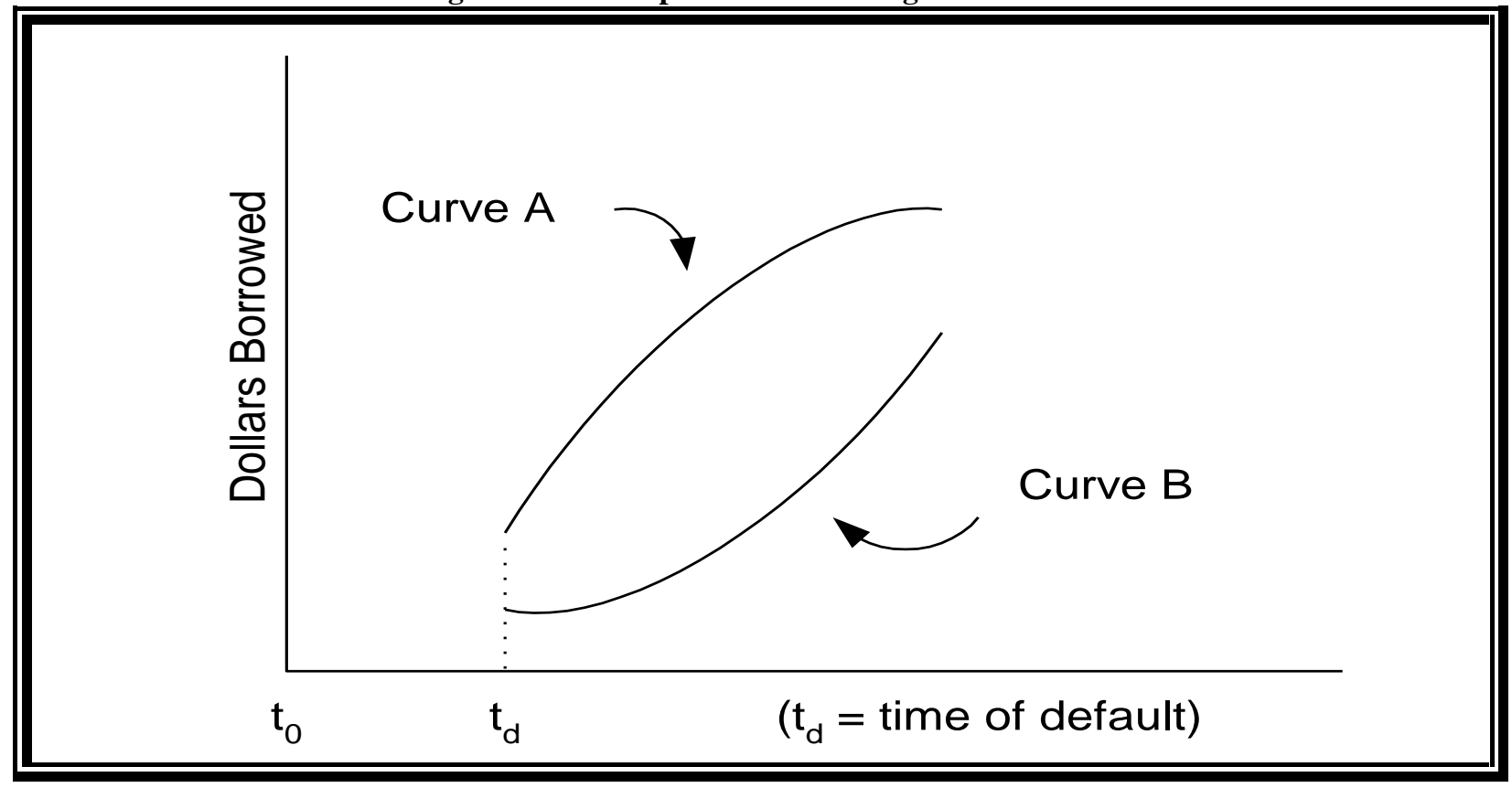

\section{Lending Modalities after Default}

From the lender perspective, it may be desirable to expand lending at a constant rate to allow the borrower to gradually absorb the funds and expand the total magnitude of the loans in reaction to the borrower's improved ability to service debt, as presented in Figure 2 .

After a default, lenders may be weary of, or even afraid of resuming lending at what may be termed a 'normal lending pattern'. The lenders may adopt a cautious stance and, for a period, curtail the quantity of loaned funds until the borrowers have given reasons to the lenders to feel more confident or to conclude that the risks associated with expanded lending have declined. Figure 3 describes this gradual or cautionary lending pattern.

Nonetheless, in some instances, the needs of the borrower are so urgent that despite great apprehension of the providers of the funds, they may be willing to recommence lending at an accelerated rate. (Commercial lenders may not be willing to do this completely on their own and such lending may be organized using the joint efforts of private and governmental agencies working in collaboration with supranational organizations such as the International Monetary Fund, the World Bank, and other development-oriented banking institutions.) This emergency or 
expansionary lending pattern is exhibited in Figure 4 indicating that the growth of the resumed lending is most rapid immediately after the time of default.

Figure 2 - Normal Lending Pattern

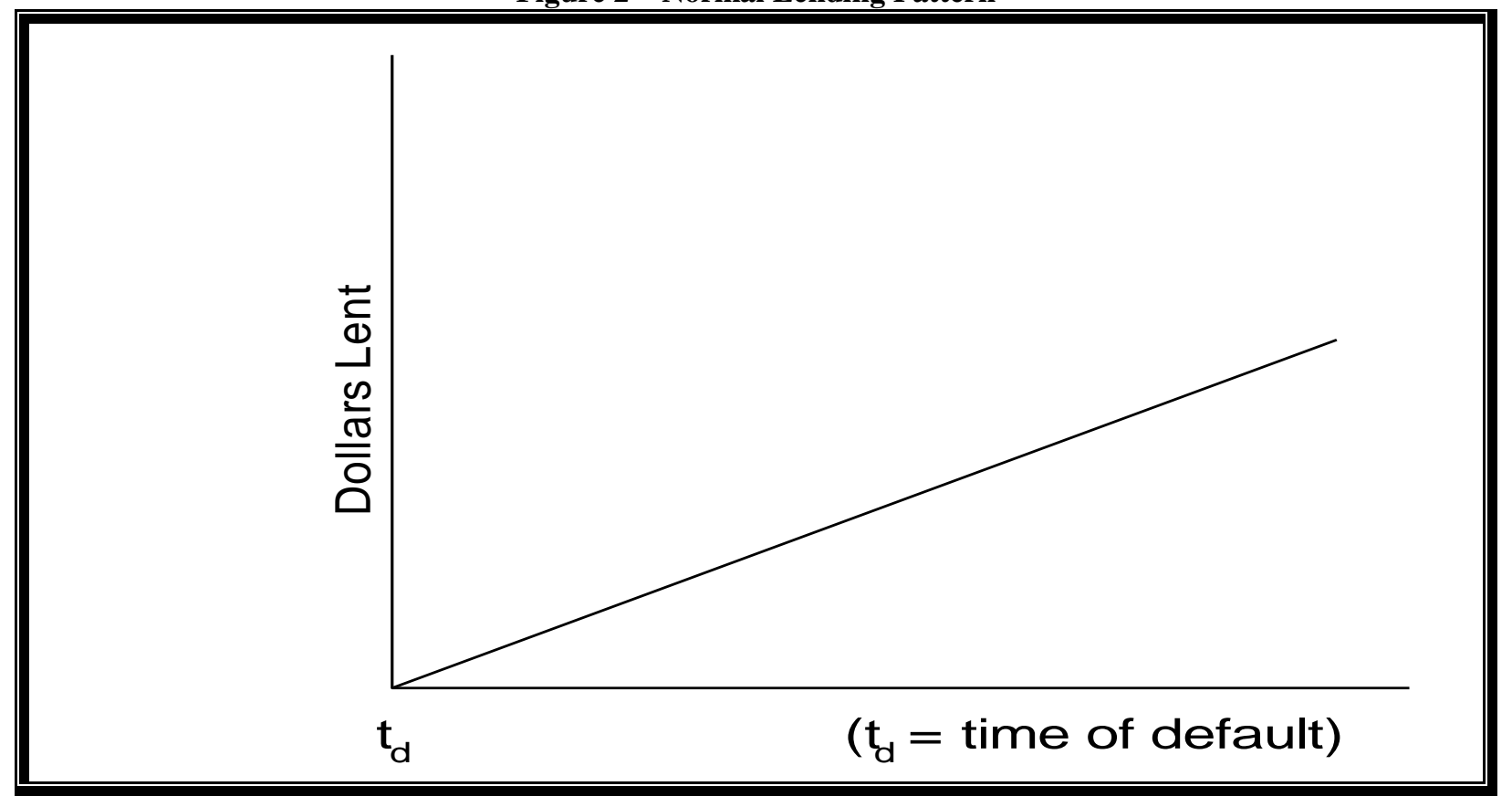

Figure 3 - Gradual or Cautionary Lending Pattern

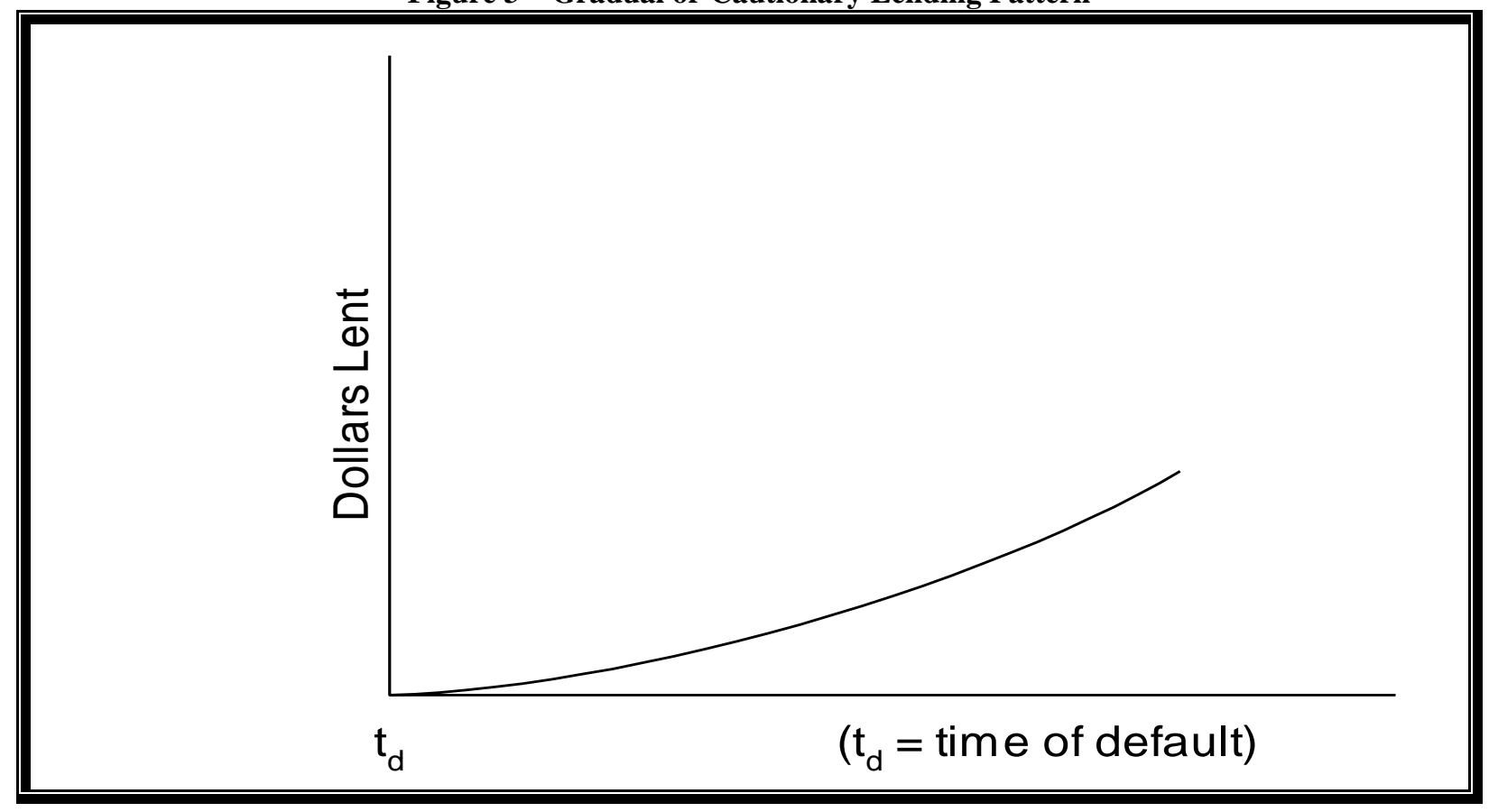


Figure 4 - Emergency or Expansionary Lending Patten

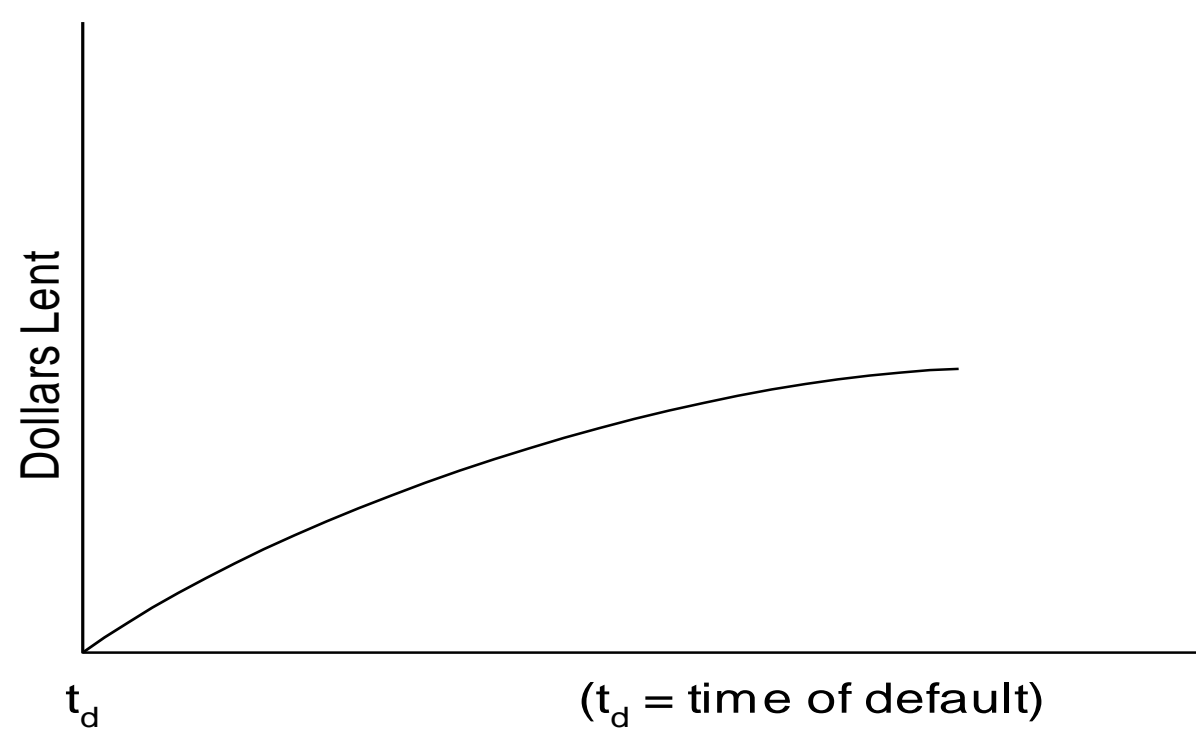

\section{Losses in Borrowing Opportunities Due to Default}

When defaults occur, the total amount of funds that can be borrowed by a country over a long period of time will be substantially smaller than the total amount that could have been borrowed in the same period, had a default event been avoided. Figure 5 isolates and identifies the components of the borrowing process.

Line A describes a borrowing schedule under non-default (or pre-default) conditions. Line B depicts the schedule of resumed borrowing after a debt default event.

The area represented by the large triangle (a, c, e) represents a normal and optimal agglomerated borrowing pattern wherein money inflows grow at a rate smaller or equal to the rate of economic growth, which makes supporting the servicing of the debt possible. In the cases of most industrialized countries, this triangle describes the default-free expansion of debt. Note that these countries may be aided in avoiding a default event by the automatic devaluation of their currencies by international capital markets and not by the actions, decisions, and policies of sovereign governments. These devaluations take place as a result of being members of the floating exchange rate system.

The area bounded by points $(a, b, d, a)$ defines the continuous inflow of funds, which the borrowing country is able to service because its economic resources are sufficient. The default point ' $b$ ' identifies the instant of interruption in borrowing, which may have been triggered by anomalies like a decline in the rate of economic growth, insufficient tax collection, political disruption, or aggressive manipulation by currency speculators.

Immediately following the point of default, borrowing under normal conditions halts, drops toward zero, and then recommences under modified circumstances at point $d$. The area bounded by points (d, c, e, d) identifies post-default borrowing. The area bounded by points $(\mathrm{b}, \mathrm{c}, \mathrm{d}, \mathrm{b})$ delineates the magnitude of the funds that the borrower could not obtain because it has committed a default.

Therefore, instead of being able to obtain a total amount represented by the bounded area (a, c, e, a), it can only acquire the amount of funds represent by the total bounded area $[(a, c, e, a)-(b, c, d, b)]$, which is also equal to the sum of the bounded areas $[(a, b, d, a)+(d, c, e, d)]$. 
Figure 5 - Simple Macroeconomic Model of Borrowing Incorporating a Default Event

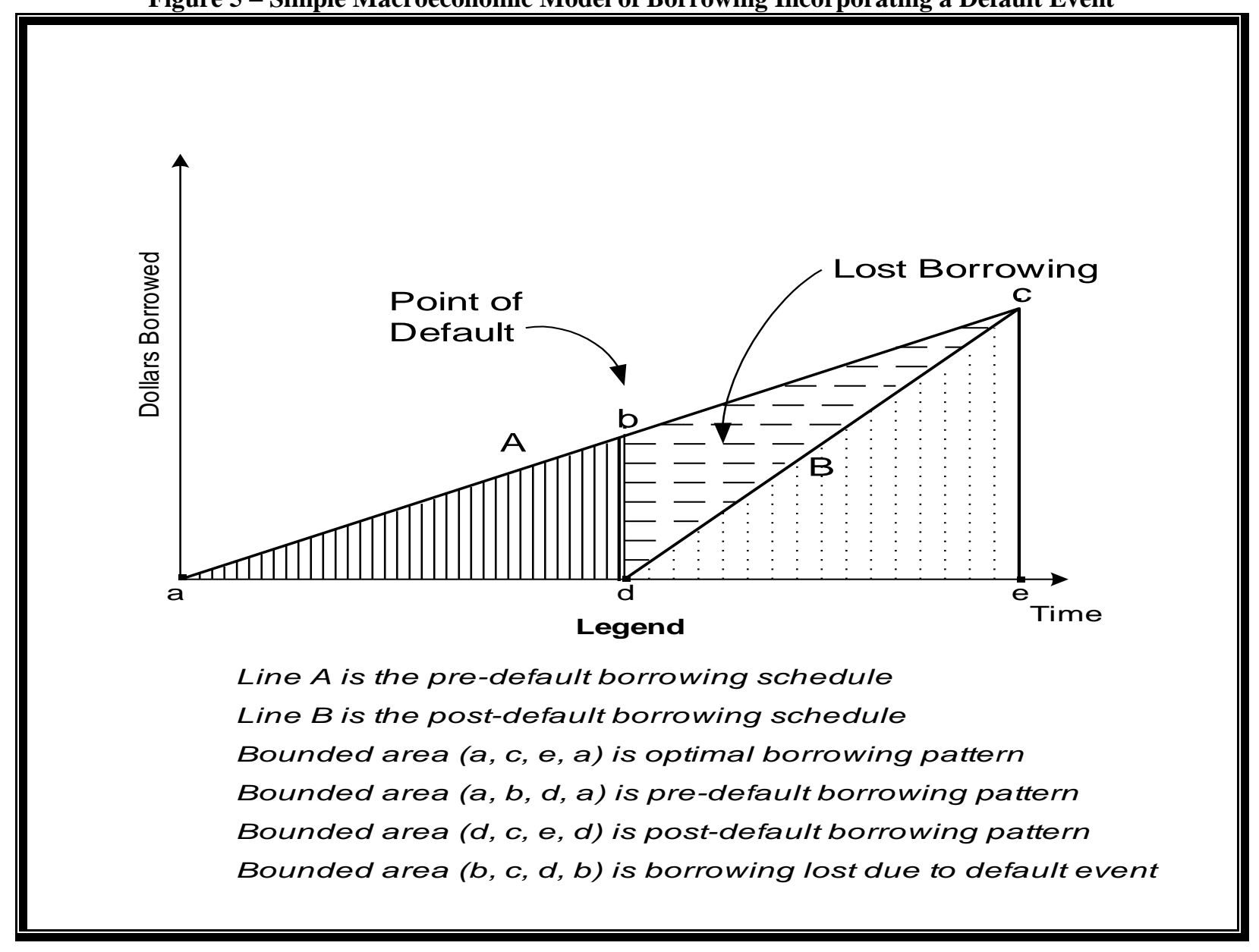

\section{From Unworthy Borrower to Predatory Borrower and from Irresponsible Lender to Predatory Lender}

Some unworthy borrowers may simply borrow too much money and fall into the chasm of debt default. Hopefully, their problems can be resolved without catastrophic pain to the borrowers (or the borrowing country), through rescheduling of debt that is harmonious with prior debt restructuring efforts. However, some unworthy borrowers deliberately build up debt over such a short period of time that the resulting enormous debt burdens make early debt defaults a certainty. These borrowers knowingly take the money and run, leaving others to cope with the crises created by the default. Such borrowers are the predatory borrowers.

Similarly, irresponsible lenders do not exert the effort to appropriately ascertain the creditworthiness of clients, and expand lending carelessly until a default occurs, causing moderate to substantial losses to lending institutions. Hopefully, as in the case of unworthy borrowers, debt rescheduling curtails or limits the financial damages to the lending institutions. However, some irresponsible lenders are so aggressive in granting loans that they burden the borrowers with debt service obligations of such enormity that early default becomes a certainty. Here too, the lenders take the money and run because these lenders pocket the upfront fees and commissions associated with making the loans, knowing all to well that soon someone else will have to deal with the financial crises they created for their own institutions. These lenders have evolved from irresponsible to predatory lenders. Figure 6 highlights the transitions from unworthy borrower behavior to predatory borrower behavior and from irresponsible lender behavior to predatory lender behavior. 
Figure 6 - Patterns of Abusive Borrower and Lender Behavior

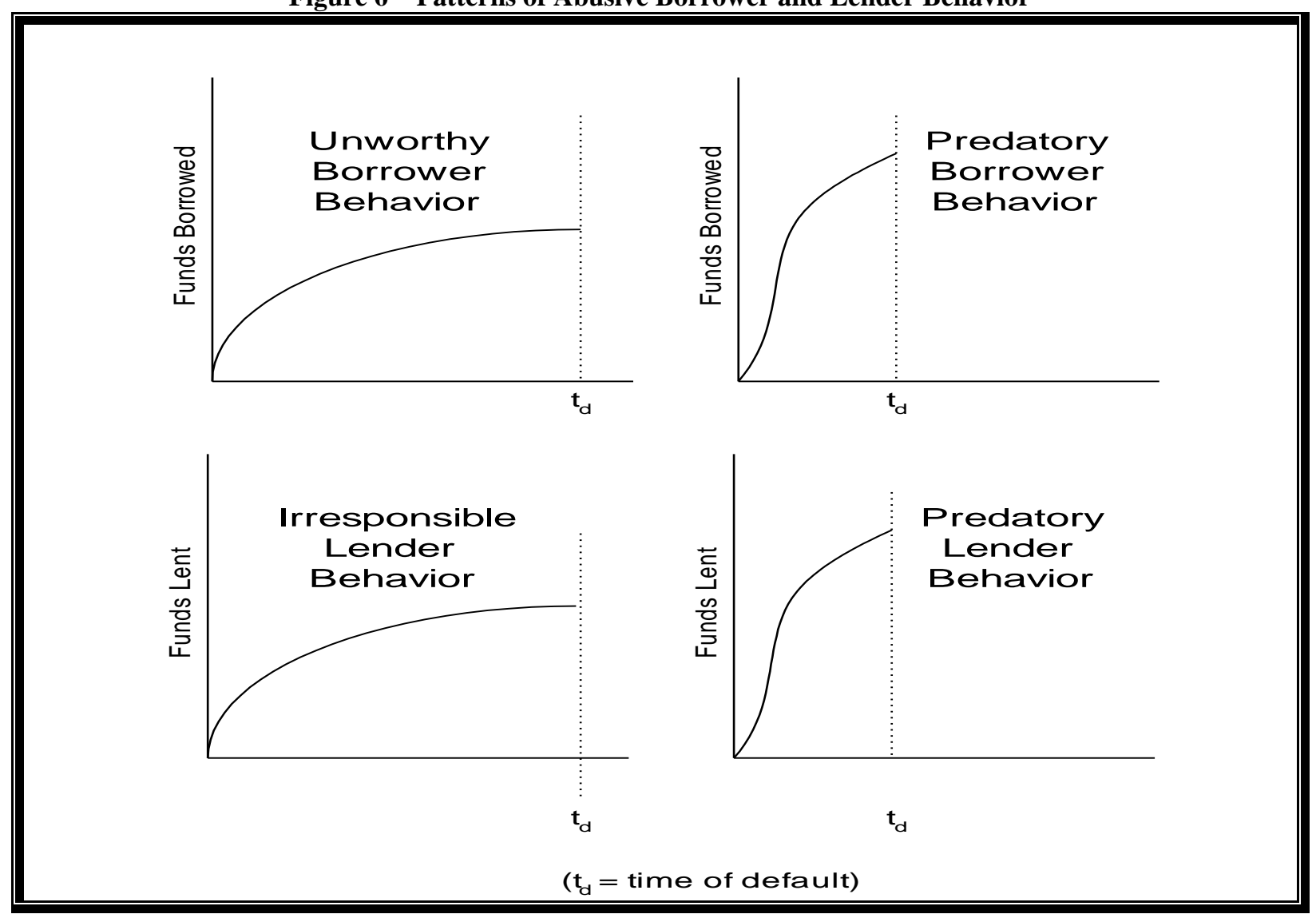

\section{The Iron Triumvirate of Debt Default}

The numerous international debt defaults ranging from large to huge were caused by varied circumstances. However, in nearly all cases, the debt crises emerged from the activities as well as the in-activities of the three major participants in large-scale international borrowing and lending: the borrowers, the lenders, and the regulators who oversee financial transactions at the national and global levels. The debt crises arise because these three players who together make up an "iron triumvirate" exhibit behaviors which qualify them for the monikers - "unworthy borrowers', 'irresponsible lenders', and 'incapable regulators'.

Unworthy borrowers are exemplified by those who aggressively increase their outstanding debt as much as they can without self-imposed limits. They expand the outstanding debt until the lenders are unwilling to extend additional loans or until they inform the lending community of their inability or unwillingness to service debt.

Irresponsible lenders are those institutions from both major and minor money capital exporting countries that are so driven to seek the short- to intermediate-term incomes made possible through international lending that they fail to prudently estimate the abilities of borrowers to service debt. These lenders may even fail to adequately take into account the historical behavior of important borrowers who in the past, with almost consistent periodicity, defaulted on their debt obligations.

Incapable regulators are the individual nation-level regulators, central bankers, and supranational financial organizations - such as the IMF - whose charters typically encompass the proper oversight of the lending/borrowing activities of commercial institutions as well as developmental agencies. As such, the perception of their role by the 
lending and borrowing community is that of a policing agent who should issue warnings whenever excessive or otherwise imprudent activity occurs. Moreover, the trust and general good faith instilled in these organizations is often so strong as to allow a false sense of security to permeate not only the lending and borrowing communities but also the individuals and companies whose funds are deposited into the coffers of the lending institutions. All too often it is these same depositors (and the taxpayers) who find themselves in the unenviable position of having to carry the burdens of the after affects of debt defaults because they held the false illusion that the oversight provided by the regulators would prevent the default events.

\section{Conclusion and Prediction}

The behavior of the borrower or lender part of the iron triumvirate may also manifest itself in various degrees of extremeness. Although problems can be caused by any one of these three groups, the associated difficulties are likely to be manageable. Modifications in corporate practices, government programs, and/or national policies may be necessary in order to forestall the arrival of major financial disruptions, as demonstrated by the circular areas A or B or C in Figure 7.

Figure 7 - Degrees of Financial Chaos Caused by the Iron Triumvirate

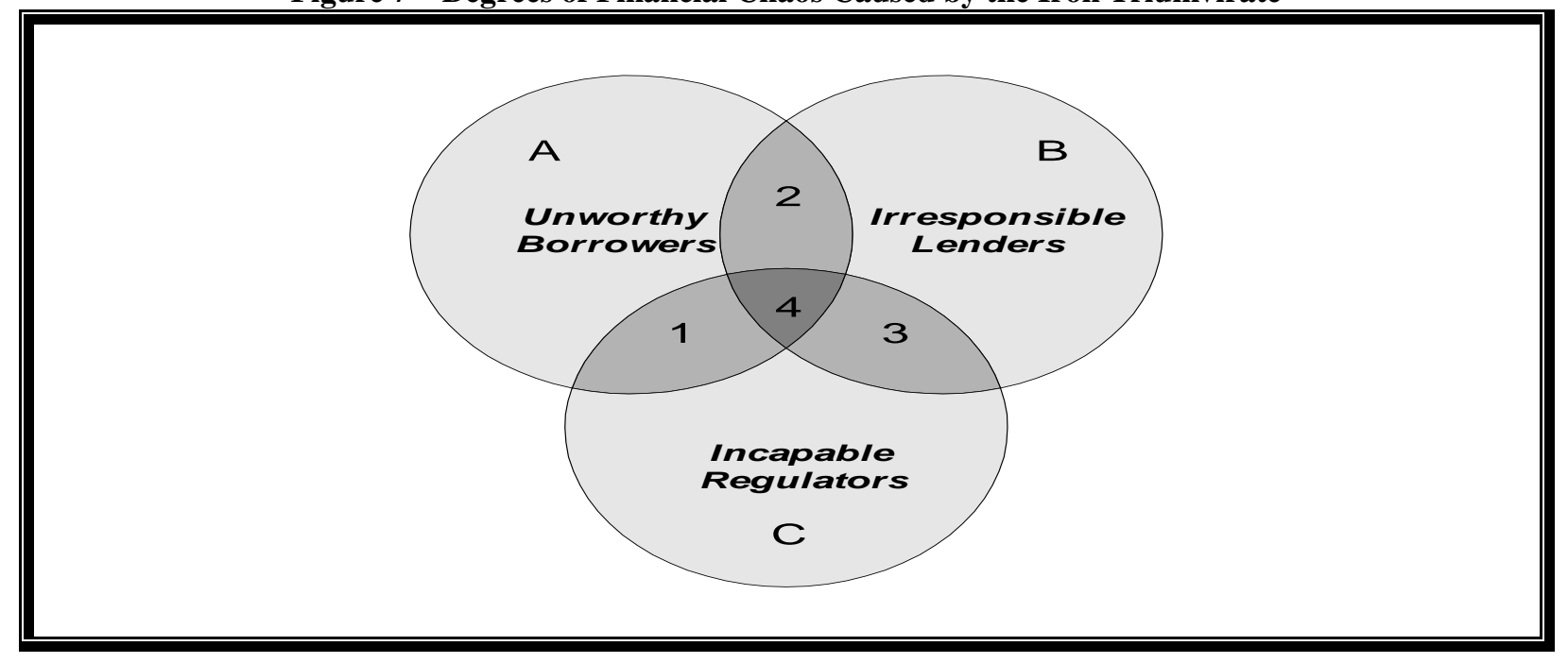

The interaction of two of these disruptive forces may lead to a more problematic scenario where the urgent counter-measures must be more dramatic and include such remedial measures as debt rescheduling and the cooperation of lenders with borrowers as well as with the legislators of the country involved, as illustrated by the shaded areas 1 or 2 or 3 .

However, the simultaneous interaction of all three forces results in the near collapse of the financial stability of the borrowing institution or country. In this case, as indicated by shaded area 4, even cooperative approaches by all three groups may not be sufficient to avoid enormous economic dislocations or societal chaos. When this congruence of forces becomes manifest, then it can be predicted that the dislocations would be very severe and the remedial measures might take years to implement and that neither the unworthy borrowers nor the incapable lenders will be able to avoid incurring enormous losses.

\section{References}

1. Department of Economic and Social Affairs, United Nations, "The Developing Economies", World Economic and Social Survey 1999, pp. 65 - 97, August 1999. 
2. Frankel, Jeffrey A., "The Asian Model, the Miracle, the Crisis, and the Fund", in Krugman, Paul, Currency Crises, (Chicago: The University of Chicago Press, 2000), pp. 327 - 337.

3. Powell, James "Reforming the International Financial System", Bank of Canada Review, Ottawa; Spring 2001, pp. $1-17$.

4. Sharma, Shalendra, "The Missed Lessons of the Mexico Peso Crisis", Challenge, Vol. 44, No. 1, January/February 2001, pp. $56-89$.

5. Vambery, Robert, and James Gabberty, "Toward a Model of Optimal Timing for International Debt Default - A Macro Level Approach.” In Moore, D. and S. Fullerton, Contemporary Readings on Global Business Trends. (Ypsilanti, MI.: Academy of Business Administration, Fall, 2001), pp. 128 - 135.

Notes 